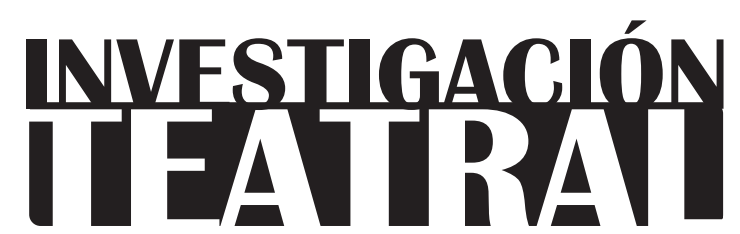

Revista de artes escénicas y performatividad

Vol. 11, Núm. 17

abril-septiembre 2020

Segunda época

ISSN impreso: 1665-8728

ISSN electrónico: 2594-0953

Universidad Veracruzana

\title{
Testimonio:
}

\section{Cultura in situ: Ensayos abiertos de la compañía Univerdanza}

\author{
Adriana León Arana*
}

\footnotetext{
* Universidad de Colima, México.

e-mail: adriana_arana@ucol.mx
}

Recibido: 07 de agosto 2019

Aceptado: 26 de noviembre de 2019

Doi: $10.25009 /$ it.v11i17.2630 
INVESTIGACIÓNTEATRAL

Revista de artes escénicas y performatividad

Vol. 11, Núm. 17

abril-septiembre 2020
Cultura in situ: Ensayos abiertos

de la compañía Univerdanza

Adriana León Arana

\title{
Cultura in situ: Ensayos abiertos de la compañía Univerdanza
}

\section{Resumen}

Cultura in situ forma parte del programa permanente de Apreciación Artística de la Dirección General de Difusión Cultural de la Universidad de Colima (U de C). A través de este programa, Univerdanza, Compañía de Danza Contemporánea de la U de C, comparte con la comunidad estudiantil la intimidad de su trabajo. En este testimonio se presentarán las formas de abordar esta actividad, estrategias implementadas, así como algunas de las experiencias y resultados más significativos que han surgido de ella.

Palabras clave: Artes escénicas, público, danza contemporánea, ensayo abierto, compañía universitaria, Colima, México.

\section{Cultura in situ: Open rehearsals of Univerdanza}

\begin{abstract}
Cultura in situ is a project that belongs to the University of Colima's permanent program of Artistic Appreciation. Through this program, the Univerdanza, Contemporary Dance Company (that belongs to the University of Colima), shares intimate aspects of its work with the student community. This testimonial article discusses how this activity was developed, what were its strategies, as well as some of the most significant experiences and results that have emerged from the program.
\end{abstract}

Keywords: Performing arts, audience, contemporary dance, open rehearsal, university company, Colima, Mexico. 


\section{Cultura in situ: Ensayos abiertos de la compañía}

\section{Univerdanza}

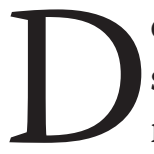
edicarse a las artes escénicas como actividad profesional desde cualquiera de sus abordajes, como la creación, la docencia o la investigación, muy posiblemente planteará un cuestionamiento constante sobre la propia labor: ¿tiene sentido hacer esto?, ¿cuál?, ¿podría hacerse mejor?, ¿qué sería mejor?, ¿estoy encontrando lo que buscaba?, ¿le es fundamental a alguien?... Estas preguntas llevan a otras y sus respuestas pueden ser esquivas y cambiantes. Existen ciertos momentos en que se tiene la impresión de que se pisa tierra más firme, y de que se sabe, o por lo menos se intuye, el rumbo y destino.

En nuestro caso como compañía de danza contemporánea, los momentos de incertidumbre se presentan frecuentemente; la práctica de la danza, en su condición inmaterial y efímera, elude las certezas. En este testimonio no se propone una forma de eliminar la incertidumbre o el desasosiego de la tarea escénica (veinte años de trabajo no han bastado para encontrar cómo hacerlo). Lo que se comparte es una actividad que ha contribuido a lograr la pertinencia, factibilidad y permanencia de una compañía de danza contemporánea en un marco universitario. Narro esta experiencia desde mi multifunción de codirectora, bailarina, coreógrafa y maestra de la agrupación, roles siempre entrelazados en todas las actividades de la compañía.

Univerdanza es un espacio para la creación, difusión e investigación de la danza contemporánea de la Universidad de Colima, cuya labor ha sido ininterrumpida desde 1999 hasta la fecha. Desde 2008 la dirección corre a cargo de quien escribe esto y de Alejandro Vera. El hecho de estar insertos en una universidad pública nos hace parte de una política cultural institucional. En la U de C todo el estudiantado, de bachillerato y 
INVESTIGACIÓNTEATRAL

Revista de artes escénicas y performatividad

Vol. 11, Núm. 17

abril-septiembre 2020
Cultura in situ: Ensayos abiertos

de la compañía Univerdanza

Adriana León Arana

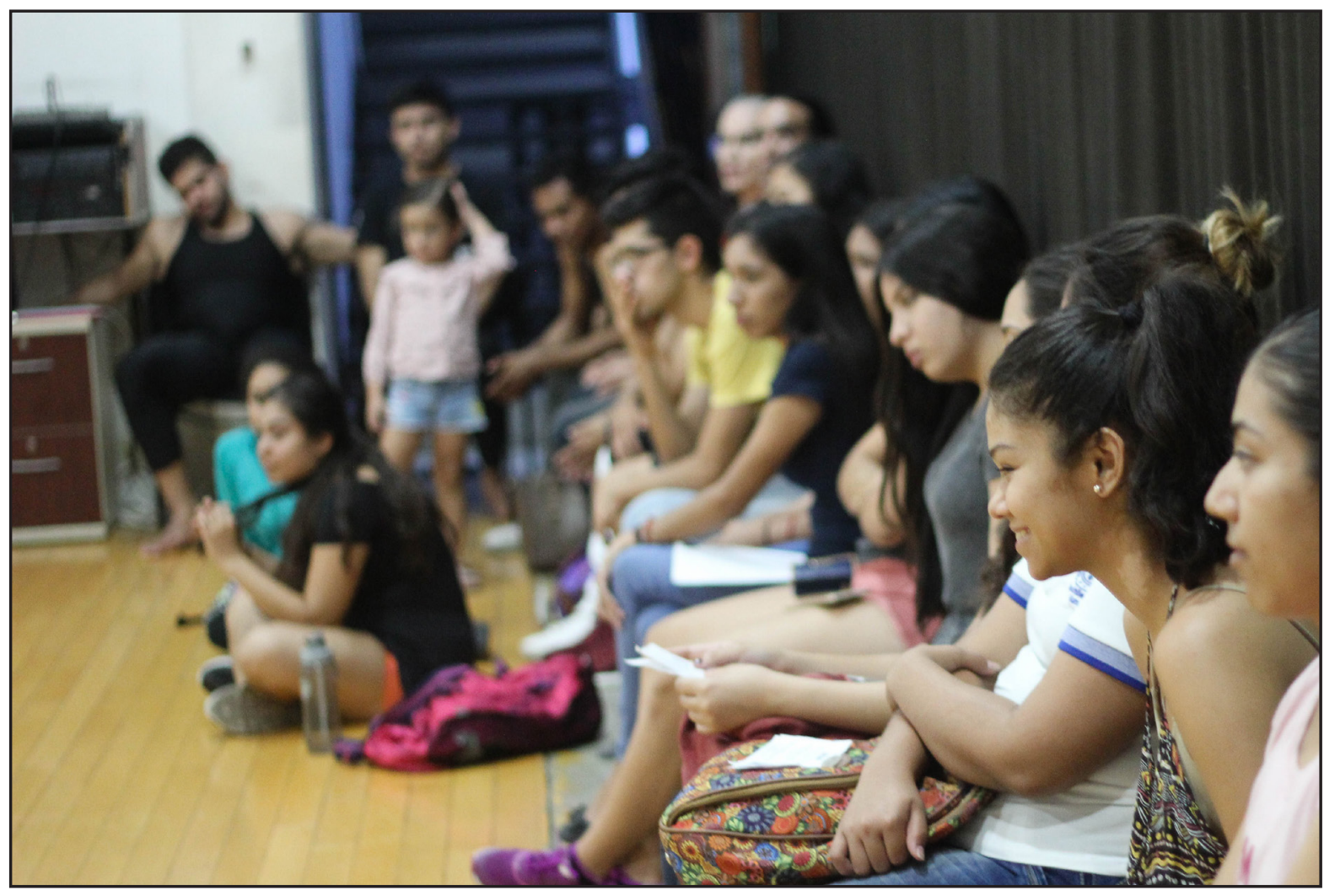

Estudiantes observan el ensayo de Univerdanza. Salón Guillermina Bravo de la Escuela de Danza del Instituto Universitario de Bellas Artes, Universidad de Colima, 2019. Fotografía de Julieta Alcaraz, cortesía de la Dirección General de Difusión Cultural de la Universidad de Colima.

de licenciatura, tiene como parte de su currícula una materia llamada Actividades Culturales y Deportivas (en los documentos curriculares se denomina "Electivas"), que se cursa durante todos los semestres de la carrera. Se le asignan 32 horas semestrales, que pueden cubrirse con práctica artística y/o deportiva en diversos espacios, como talleres libres de arte, entrenamientos deportivos, etcétera, o bien, asistiendo como público a eventos de su elección.

Todas las acciones referentes a la acreditación de actividades culturales (programación, suma y registro de horas en el sistema de control escolar, difusión, etcétera) son organizadas por la Dirección General de Difusión Cultural (DGDC), en su Programa Permanente de Apreciación Artística. Una de las actividades de este programa es $\mathrm{Cul}$ tura in situ, que consiste en la asistencia a ensayos abiertos de agrupaciones artísticas, 
y que acredita entre tres y cinco del total de 32 horas requeridas por semestre; la entrada a los ensayos siempre es sin costo y en horarios adecuados a las posibilidades de los estudiantes. Univerdanza ha participado en Cultura in situ desde que este programa se inició, en 2011. A continuación comparto algunas de las experiencias más significativas que surgieron al abrir las puertas de nuestro Salón Guillermina Bravo a jóvenes estudiantes universitarios, así como las principales estrategias que hemos puesto en juego.

\section{El salón como espacio de contacto íntimo}

Eliminando gradualmente lo que se demostraba como superfluo, encontramos que el teatro puede existir sin maquillaje, sin vestuarios especiales, sin escenografía, sin un espacio separado para la representación (escenario), sin iluminación, sin efectos de sonido, etc. No puede existir sin la relación actor-espectador, en la que se establece la comunión perceptual, directa y "viva” (Grotowski 13).

Para Univerdanza una pregunta guía ha sido: ¿cómo podemos establecer una conexión profunda con el espectador? A partir de esta inquietud hemos considerado que los ensayos abiertos son una oportunidad para encontrar maneras de profundizar nuestros vínculos con el público. Su frecuencia ha variado desde uno, realizado cada dos meses, hasta una vez por semana; desde 2017 se llevan a cabo dos veces al mes, porque, con la experiencia vivida, hemos detectado que esta periodicidad permite que el diálogo se dé fluidamente e influya en nuestros procesos de forma positiva.

En la compañía empleamos una clasificación general de nuestros tipos de ensayos, que guarda relación directa con su finalidad. Esta distinción se hace a partir del conocimiento empírico de la danza, no es cerrada, pueden darse variantes y combinaciones. Como ensayo abierto puede llevarse a cabo cualquiera de los siguientes:

-Ensayos de montaje. Se refieren al tiempo en que se corporizan las ideas. Se busca la construcción de sentido con el lenguaje del cuerpo. Además de memorizar el movimiento, el bailarín debe apropiarse de la intención creadora y reinterpretarla, de modo que quien está componiendo considere satisfactoriamente transmitida su idea. Hacer que la danza sea requiere un método de construcción, que es variable entre obras y entre coreógrafos(as).

-Ensayos de remontaje o reposición. Son aquellos que se realizan de una obra previamente estrenada, pero que no tiene al elenco completo o hace tiempo que no se presen- 
ta. Un remontaje es una oportunidad de replantearse lo que se hizo, una ocasión para revisitar el proceso creativo y entrar en diálogo con él. Como resultado de este nuevo abordaje puede ser que se introduzcan algunas modificaciones a la obra.

-Ensayos de repertorio. En ellos se rememora y ajusta repertorio vigente. Cuando el elenco permanece en la compañía, pero no se ha presentado al público en fechas recientes, se requiere un tiempo específico para desplegar este ejercicio de memoria corporal-cinética, así como de revisión del archivo de video.

-Ensayos de corrida de programa. Se llevan a cabo una vez que las piezas coreográficas están listas por separado, en el orden y tiempo en que el programa se presentará al público. Principalmente, se trata de cuidar el ritmo general de la función, tanto para el espectador como para los intérpretes. Además se prepara la resistencia física, así como los cambios requeridos en la interpretación de cada obra.

El Salón Guillermina Bravo, de la Escuela de Danza del Instituto Universitario de Bellas Artes (sede de Univerdanza), mide 14 por 14 metros. No cuenta con iluminación teatral ni vestiduras o rompimientos. Es espacio vacío. Para los ensayos abiertos, se cubre el espejo y se colocan bancas de madera y sillas para el público.

Las actividades de la compañía no están planeadas en función del ensayo abierto, por lo que el público observa lo que en ese momento efectivamente está sucediendo en el grupo; en cada ocasión intentamos la "eliminación de lo superfluo", para privilegiar el contacto con el público desde el movimiento”. Por lo general, la hora de llegada coincide con el final de nuestra clase de entrenamiento. Al finalizar ésta, explico de qué se trató la clase, lo que se hará en el ensayo y por qué. También comparto si el entrenamiento ha tenido ajustes y adaptaciones para el proceso en cuestión, con el fin de lograr alguna habilidad en particular, o lo que sea que se esté buscando.

En cada ocasión, abrimos una charla hacia el final, dando espacio para preguntas y comentarios del público, cuyo tamaño puede variar (entre 20 y 100 personas). Es interesante que los asistentes suelen estar dispuestos a participar en estos diálogos y en las dinámicas en que les pedimos que se involucren. Si bien están allí por la obligación de cubrir una materia (en su mayoría, porque también damos entrada a público general), el hecho es que eligieron entre una amplia oferta la opción de presenciar un ensayo de danza contemporánea. Como toda la Universidad está implicada en esta actividad, podemos tener reunidos a estudiantes de bachillerato y de licenciatura de diferentes áreas del conocimiento.

Hemos tenido asistentes que llegan al inicio de un montaje y deciden acudir de forma continua durante varios meses para ver cómo avanza. Eso permite que, por ejemplo, un estudiante de preparatoria nos exprese juicios y opiniones como "esta persona se equivocó en el principio", o "al bailarín de enfrente le salió mal esto", o "aquí ella se rio cuando debía verse amorosa". 
En los ensayos abiertos existe la potencia de la cercanía con el público, de modo que se hacen más evidentes la expresión, el esfuerzo, la respuesta a los estímulos. Al no usar iluminación teatral ni escenografía en general, intentamos concentrarnos en el poder del cuerpo, su expresión y su comunicación. Esto nos ha llevado a compartir, con el público que llega a los ensayos, lo que constituye el laboratorio de movimiento, concepto que explicamos a los asistentes del siguiente modo: aunque hace mucho tiempo que este término se reconoce en el campo profesional y es parte de su argot, no es común identificarlo con la práctica dancística, pero sí se realiza. Entendemos laboratorio en el sentido amplio de experimentar con el fin de encontrar los movimientos y sus combinaciones que sean más pertinentes para "el mundo que queremos poner a existir" a través de la danza. En este sentido, también tomamos como referencia las palabras de Jorge Dubatti, porque creemos que es una forma clara de exponer al público la intención creativa de nuestro trabajo: "la función del artista no es tanto expresar(se) o comunicar(se), sino poner un mundo a existir" (Cartografía teatral 39).

Los asistentes observan cómo se desarrolla este laboratorio y a veces los hacemos participar con su propio cuerpo; por ejemplo, les decimos: "ustedes nos pueden ayudar, si yo estoy haciendo este movimiento (se muestra) y quiero interactuar con esta persona (se muestra la interacción con alguien del público, que responde instintivamente al estímulo)". En ocasiones les pedimos opinión sobre las soluciones de movimiento: ¿qué te parece si lo hago de esta forma?, ¿me dejas verlo en tu cuerpo?, ¿cómo lo sentiste mejor? Entonces, el público comienza participar de la acción y así es como se puede ir dando un diálogo que incluye movimiento y sus respuestas. Todo el tiempo que compartimos nuestro trabajo estamos explicando lo que hacemos, de diferentes formas. A veces los ponemos a bailar, en otras ocasiones les solicitamos comentarios de apreciación personal sobre lo que ven y escuchan.

Gracias a estos años de Cultura in situ, quienes han asistido a nuestro salón comprenden que hacer danza entraña una serie de actividades y saberes específicos de la profesión. Además, sin ser especialistas, pueden darse cuenta de cuándo sí y cuándo no se está llegando al resultado esperado, y lo mencionan en sus comentarios. Esto no siempre es cómodo para los y las intérpretes, porque no es común que el público nos diga "te equivocaste en el brinco", "tu emoción no parece ser lo que estás diciendo que debe ser", "te falta fuerza", etcétera, pero es muy útil, porque nos recuerda que estamos intentando entrar en conexión con quien nos observa, que es el fin último de nuestro trabajo, y lo hacemos partícipe de nuestro camino, intención y finalidad. De este modo, la audiencia es parte del proceso y de la obra.

En esta actividad también hacemos referencia a lo que Howard Gardner llama inteligencia cinético-corporal, una de las siete distintas inteligencias que define: 
INVESTIGACIÓNTEATRAL

Revista de artes escénicas y performatividad

Vol. 11, Núm. 17

abril-septiembre 2020
Cultura in situ: Ensayos abiertos

de la compañía Univerdanza

Adriana León Arana

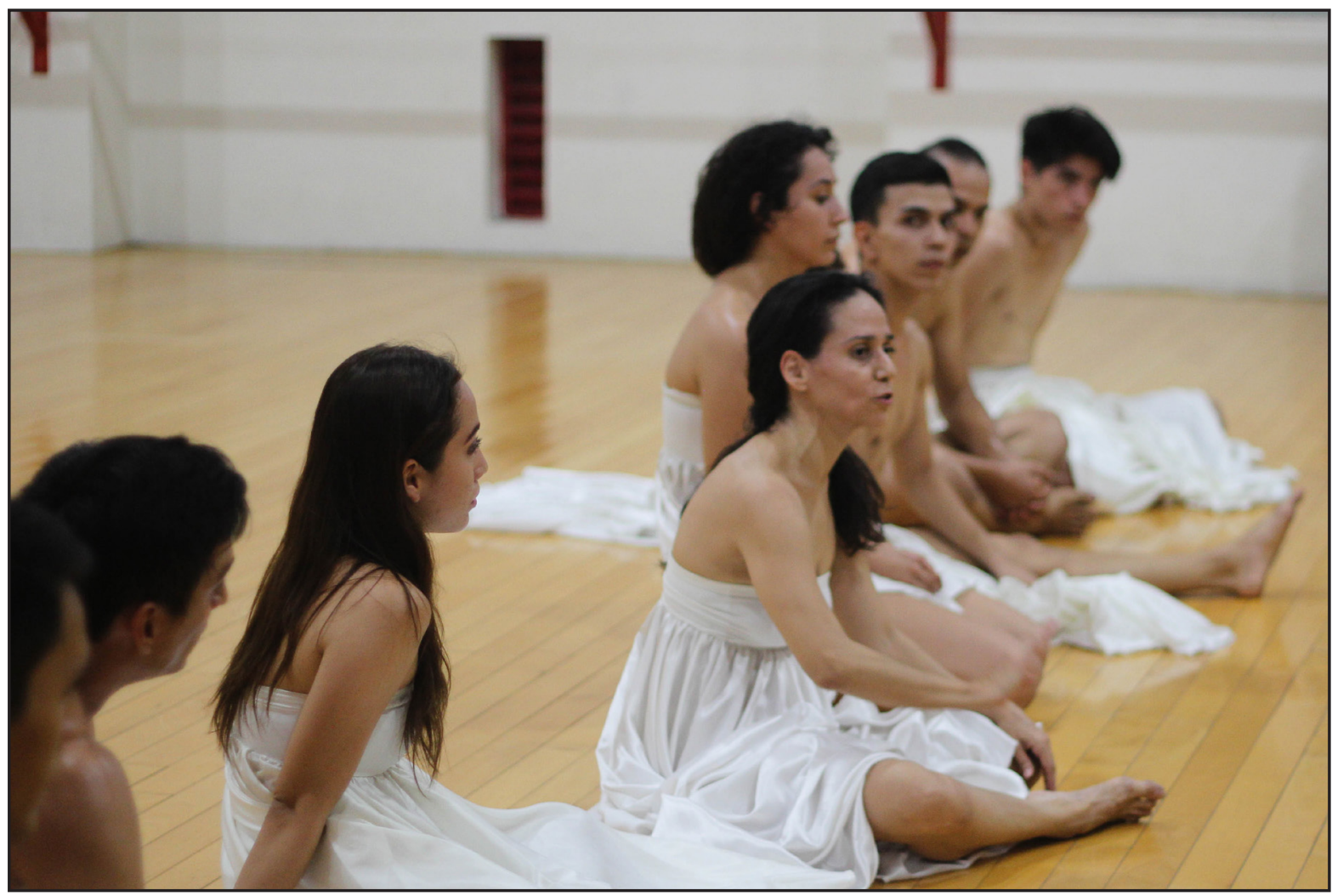

La compañía realiza un diálogo con el público al finalizar el ensayo. Salón Guillermina Bravo de la Escuela de Danza del Instituto Universitario de Bellas Artes, Universidad de Colima, 2019. Fotografía de Aura Benavides, cortesía de la Dirección General de Difusión Cultural de la Universidad de Colima.

Pese a nombrar primero a las inteligencias lingüística y lógico-matemática, no lo hago porque piense que son las más importantes: de hecho, estoy convencido de que las siete inteligencias tienen el mismo grado de importancia. En nuestra sociedad, sin embargo, hemos puesto a las inteligencias lingüística y lógico-matemática, en sentido figurado, en un pedestal [...] La inteligencia corporal y cinética es la capacidad de resolver problemas o para elaborar productos con el cuerpo, o partes del mismo. Bailarines, atletas, cirujanos y artesanos muestran, todos ellos, una inteligencia corporal y cinética altamente desarrollada (Inteligencias múltiples 26).

Compartir este concepto nos permite explicar, con la voz de un científico reconocido, que la forma de inteligencia necesariamente aplicada en la danza es particular y susceptible de desarrollarse como cualquier otra. 
Aunado a que el esfuerzo observado por el público es inmediato (no solo en el sentido de esfuerzo físico, sino también en el de la expresión), cuando el público participa con movimiento, su accionar es una respuesta orgánica al estímulo, no parte de ideas preconcebidas o heredadas de lo que debe ser o no en la danza. Tampoco pasa por el filtro del entrenamiento técnico que quienes hacemos danza hemos corporizado. Mirar a los asistentes desenvolverse en el salón funciona como guía; el abanico de respuestas se amplía, se matiza. Por ejemplo, para el montaje de la obra Azul Blue (2017), que sería con música en vivo con la cantante y poeta Indira Torres, el propósito rector de la creación era proveer al espectador una experiencia que le permitiera crear puentes de conexión entre la obra poética, la musical, la coreográfica y sus propias experiencias. Pretendíamos encontrar una relación que respondiera a la transdisciplina en el sentido expuesto por Edgar Morin:

Corresponde a Basarab Nicolescu una comprensión de la transdisciplina que enfatiza el "ir más allá" de las disciplinas, trascenderlas. La transdisciplina concierne entonces a una indagación que a la vez se realice entre las disciplinas, las atraviese -el a través de-, y continúe más allá de ellas (párrafo 14).

Deseábamos también que la audiencia se involucrara de manera íntima a pesar de la distancia real, impuesta por las dimensiones del teatro en que la obra se estrenaría. Creíamos que esta búsqueda debía empezar por la forma de abordar nuestra interpretación.

Coincidió que el primer ensayo de Azul Blue al que se integraron la cantante y los músicos (Show Bravos) ${ }^{1}$ fuera abierto. En lugar de que los asistentes se sentaran al frente como en otras ocasiones, les pedimos que se sentaran en la duela rodeando a los músicos. Los y las intérpretes de Univerdanza se intercalaron en el público. Desde el principio les compartimos nuestras intenciones y les hicimos saber que era la primera vez que estábamos juntos en el salón; incluso, explicamos cómo habíamos elegido los poemas. En esa sesión en particular, el público estuvo bailando y participando, para que nosotros también lográramos recrear la atmósfera de ser parte de la acción. Fue una exploración colectiva en la que tomamos parte poeta, músicos, público, intérpretes y coreógrafos(a).

De esa sesión se tomó video, la improvisación musical funcionó como guía general para la estructura de la obra, se capturó un ambiente festivo y a su vez de gran expectativa, que pudimos recrear durante el montaje. El día del estreno tuvimos un abundante público (500

1 Shows Bravos, conformado por Indira Isel Torres Cruz y Martín Rivera, "es el reflejo de las influencias que inevitablemente se adoptan en la casa, en la calle, en el escenario, en la computadora; en las cosas que amas, en las cosas que odias. Improvisamos como sentimos y queremos que la gente que viva este show sienta con nosotros" ("Presentan Shows Bravos" párrafo 2). 
personas, aproximadamente), y creemos que en parte fueron quienes acudieron a aquel primer ensayo, sus acompañantes e invitados.

En Univerdanza hemos llegado a clasificar nuestro trabajo en tres categorías que mantienen entre sí una relación recursiva:

-Organización: este aspecto consiste en explicar la relación de la compañía con el entorno universitario, así como su funcionamiento interno.

- Metodología, procesos de trabajo cotidiano: se hace mención a la forma de proceder en el trabajo cotidiano previo a la presentación ante el público (clases y ensayos). Se incluye también la descripción de los pasos que se siguen para la escenificación de las obras coreográficas (diseño y realización de vestuario, escenografía, iluminación, material impreso, grabaciones musicales).

-Creación: se observa la manera en que se conformó un programa de concierto, así como la lógica particular y los métodos de construcción aplicados por algunos coreógrafos de Univerdanza para darle cuerpo a una idea a través de la composición coreográfica (poniendo énfasis en lo que ocurre dentro del salón de danza) (León 14).

En los ensayos abiertos se han compartido experiencias y acciones relacionadas con los tres aspectos; por ejemplo, en lo referente a los de organización, tuvimos la participación del público asistente a los ensayos abiertos en una campaña de recaudación de fondos.

El septiembre de 2016, Univerdanza recibió una invitación para que, el año siguiente (mayo de 2017), presentaran su trabajo en el 92Y de la ciudad de Nueva York, dentro de la temporada Cinco de Mayo: Mexican Choreographers from City to Mountains, en el Buthenweiser Hall del Harkness Dance Center. La institución convocante ofrecía el espacio para función y ensayos, publicidad y programación. Los gastos de transporte, hospedaje y alimentación debían correr por cuenta de la compañía. La gira podía ser muy complicada y costosa, sin embargo, constituía la oportunidad única de presentarse en una de las capitales de la danza contemporánea y en un espacio escénico emblemático para su historia. Para realizarla, se organizó un plan de acción que incluyó dos funciones (31 de marzo y 27 de abril de 2017), con el propósito de recaudar fondos para los gastos de hospedaje de ocho personas por diez días.

A partir de septiembre, en los ensayos abiertos, se expuso al público cada etapa del proceso en que estábamos; los estudiantes asistentes se involucraron al grado de ayudarnos con la venta de boletos, dieron seguimiento a la adaptación de las obras, además de darse cuenta de las necesidades y complicaciones que significaba la organización de la gira. Así, compartieron cada dificultad o logro, por ejemplo, cuando celebraron con nosotros que a los integrantes que no tenían visa para ingresar a Estados Unidos ésta les fuera finalmente otorgada. 
Para una compañía de danza contemporánea mexicana tener alrededor de 600 personas en una función es una numerosísima concurrencia. En ambas hubo esa cantidad aproximada. Si bien sabemos que el apoyo institucional fue indispensable para lograrlo y se nos otorgó plenamente, también creemos que, en este caso, las recomendaciones entre las personas para asistir y apoyar fueron fundamentales para alcanzar la meta. Muchas asistieron expresamente para contribuir a la gira, sabían que, con su pago por ver nuestra función, Univerdanza pagaría su alojamiento en Nueva York. Ese periodo se asemejó a una fiesta colectiva que nos enseñó tanto como la misma gira y que fortaleció nuestro sentido de pertenencia a la ciudad que habitamos y a la institución que representamos. Me atrevería a decir que fue uno de los aspectos más valiosos de la experiencia: estrechar así los lazos con el público mayormente universitario.

\section{La presencia del público como experiencia significativa}

Cuando cuentas con la mirada del otro durante el proceso de creación, en la cercanía, la forma en que requieres apropiarte del lenguaje cambia; prestas mayor atención con los sentidos a la respuesta cinésica provocada en quien está enfrente, percibes con el cuerpo sus pequeños cambios en la respiración, en la mirada, en la tensión corporal. A la luz del día y a corta distancia, la reacción del espectador es transparente, inmediata, aun antes de abrirse el diálogo. Esto ayuda en el intento de poner atención plena al lenguaje del cuerpo, el discurso, la nueva realidad inventada. Te acerca al contacto profundo con el público y te expresa qué tan lejos o cerca estás de conseguirlo. El mundo que deseas poner a existir se va cristalizando (o no) también frente a tus ojos, porque te observas en la mirada del otro.

El eje de la Responsabilidad Social que rige a la Universidad de Colima en todas sus actividades (por supuesto, nosotros incluidos), nos recuerda que, como compañía universitaria, el trabajo que realizamos es para el público. No podemos ser entes aislados expresándose o queriendo construir mundos imaginarios y maravillosos que nadie va a recibir. Necesitamos estar todo el tiempo buscando los mejores, más cercanos y certeros caminos para estar en contacto con la audiencia desde nuestra intención creadora.

La experiencia nos ha demostrado que esta actividad sirve como una forma de entrenamiento de la presencia escénica, que además contribuye a desarrollar la capacidad de adaptación de nuestros integrantes a los diferentes proyectos que emprendemos y a las diversas condiciones de los espacios en que presentamos nuestro trabajo. También hace que los bailarines(as) sean más conscientes de la respuesta del público y que puedan conservar el nivel alcanzado y la concentración ante diferentes formas de reacción de la audiencia. 
INVESTIGACIÓNTEATRAL

Revista de artes escénicas y performatividad

Vol. 11, Núm. 17

abril-septiembre 2020
Cultura in situ: Ensayos abiertos

de la compañía Univerdanza

Adriana León Arana

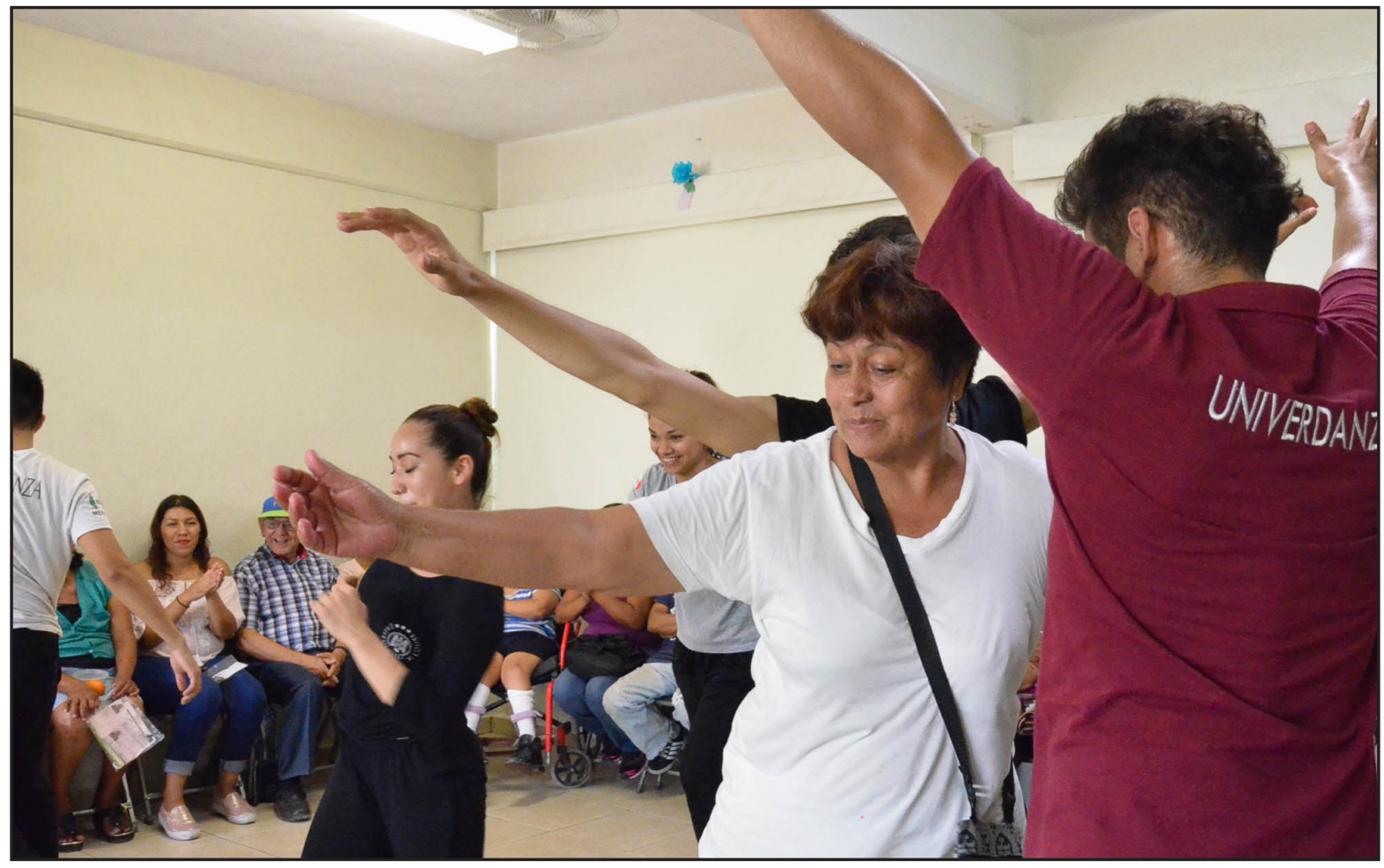

El público participa en la coreografía en compañía de Univerdanza. Centro de Desarrollo Comunitario de la Colonia Mirador de la Cumbre II, Colima, 2019. Fotografía de Luis Ángel Magallanes, cortesía de la Dirección General de Difusión Cultural de la Universidad de Colima.

Por lo expuesto, creemos que, como bailarines o artistas de la escena, la presencia permanente del público en nuestro espacio de trabajo nos impide aislarnos. Podemos estar ensimismados mientras hacemos danza, pero con la práctica sistemática de abrir nuestros ensayos durante todo el año no hay esa posibilidad. Nos mantenemos en contacto, y tenemos que hacerlo de la mejor manera. Nuestra finalidad última como compañía, en palabras de Grotowski, "es la comunión perceptual, directa y 'viva" (13) entre nosotros y el público, y Cultura in situ nos lo recuerda y nos impulsa a intentarla cada día.

\section{Fuentes consultadas}

Dubatti, Jorge. Concepciones de teatro. Poéticas teatrales y bases epistemológicas. Buenos Aires: Colihue, 2009. 
Dubatti, Jorge. Cartografía teatral. Introducción al teatro comparado. Buenos Aires: Atuel, 2008

Gardner, Howard. Inteligencias múltiples. La teoría en la práctica. Barcelona: Paidós, 2003. Gardner, Howard. Mentes creativas: una anatomía de la creatividad vista a través de las vidas de Sigmund Freud, Albert Einstein, Pablo Picasso, Igor Stravinsky, T.S. Eliot, Martha Graham y Mahatma Gandhi. Barcelona: Paidós, 1998.

Grotowski, Jerzy. Hacia un teatro pobre. Traducido por Margo Glantz, Ciudad de México: Siglo xxi, 2011.

León Arana, Adriana. Univerdanza: Compañia de Danza Contemporánea de la Universidad de Colima: procesos de organización, metodología y creación. Tesis de Maestría en Artes Escénicas, Universidad Veracruzana, 2011.

Morin, Edgar. “¿Qué es transdisciplinariedad?”. Edgar Morin, Sitio Web Oficial Internacional, Multiversidad Mundo Real Edgar Morin, www. edgarmorinmultiversidad.org/ index.php/que-es-transdisciplinariedad.html, consultado el 8 de abril de 2019.

"Presentan Shows Bravos en el Museo de Artes Populares". ENTÉRATE, Universidad de Colima, 30 de abril de 2015, www.ucol.mx/enterate/nota.php?docto=1259, consultado el 28 de enero de 2020. 